\title{
Experimental Study and Comparative Numerical Analysis of the Mechanical Behavior of Extended End-Plate Connections with End-Plate Stiffeners
}

\author{
Shizhe Chen ${ }^{1,2}$, Chao Zhou ${ }^{2}$ and Zhan Wang ${ }^{*}, 1,2$ \\ ${ }^{I}$ State Key Laboratory of Subtropical Building Science, South China University of Technology, Guangzhou 510640, \\ China \\ ${ }^{2}$ School of Civil Engineering and Transportation, South China University of Technology, Guangzhou 510640, China
}

\begin{abstract}
To investigate the influence of end-plate stiffeners on the initial rotational stiffness of extended end-plate internal joints, an experimental program was carried out to investigate the rotational behavior of the joints. Two finite element methods (FEMs) were proposed using ABAQUS software. The stress distribution, plastic development, and deformation characteristics of extended end-plate joints were determined from a comparison of the results of experiments and numerical analyses, and a calculation method for the initial tensile stiffness of the end-plate stiffener was proposed. This investigation presented herein demonstrates that (1) the angle and thickness of the stiffener strongly influence the initial tensile stiffness of the joint; and (2) component-based FEMs can accurately reflect the entire loading process of joints in a simple and efficient manner.
\end{abstract}

Keywords: End-plate stiffener, finite element method, experimental investigation, modified component method.

\section{INTRODUCTION}

In traditional designs, joints are assumed to be ideally pinned or fully rigid; however, joints have finite rotational stiffness and can be considered as semi-rigid. An important aspect in the analysis of these joints is that their behaviors are decoupled from the analysis of the structure. However, the rotational behavior of joints should be considered as it has a profound influence on the optimization of the design of the entire steel frame. As specified in Eurocode 3, the component method can be used to predict the mechanical behavior of steel joints or composite joints [1]. In this method, the panel zone is appropriately simulated by a combination of mechanical components, and a mechanical model can be established by the use of linear or non-linear springs, which are based on the mechanical components properties. These components, which represent a specific part of a joint depending on the type of loading, have different functions for structural performance [2]. Many researchers have proposed simplified mathematical models and calculation methods for the initial rotational stiffness of semi-rigid joints [3-6]. However, most of these studies focused mainly on conventional joints, while few discussed unconventional joints such as joints containing stiffeners to enhance the joint stability and torsion resistance.

An extended end-plate connection is a typical type of semi-rigid joint $[7,8]$. In fact, the behaviors of extended end-

*Address correspondence to this author at the State Key Laboratory of Subtropical Architecture Science, Department of Civil Engineering and Transportation, South China University of Technology, Guangzhou 510640; Tel: (+86)13825045880; Fax: +86-020-87113421;

E-mail: wangzhan@scut.edu.cn plate joints such as their moment resistance, initial rotational stiffness, and rotation capacity have important effects on the design of the entire steel frame. The application of an endplate stiffener could improve the mechanical behavior of a joint to optimize the performance of the beam. Meanwhile, the use of a thin end plate could contribute to the design optimization.

In this paper, an experimental investigation and finite element analysis of the mechanical behaviors of extended end-plate joints with end-plate stiffeners were carried out. The influence of end-plate stiffeners on joint behavior was examined, and the end-plate stiffener was introduced into the component method. A comparative study of two finite element methods (FEMs) is also presented.

\section{TEST PROGRAM}

\subsection{Structural Model}

Two specimens with different extended end-plate internal joint configurations were employed (Fig. 1). All the specimens contained four bolt rows, and each row contained two symmetrical bolts. The end-plate stiffeners were used only at the left side of the joint in each test. The specimens were Q235 steel (nominal yielding stress $f y=235 \mathrm{MPa}$ ), and the bolts were high-strength friction-grip bolts (Grade 10.9). The details of the material parameters of the specimens are listed in Table 1, and the material properties of the steel were obtained from standard tensile tests on coupons (Table 2). Four standard specimens, made from the column web, beam web, end-plate stiffener and end-plate respectively, were tested on the universal testing machine. All bolts were 


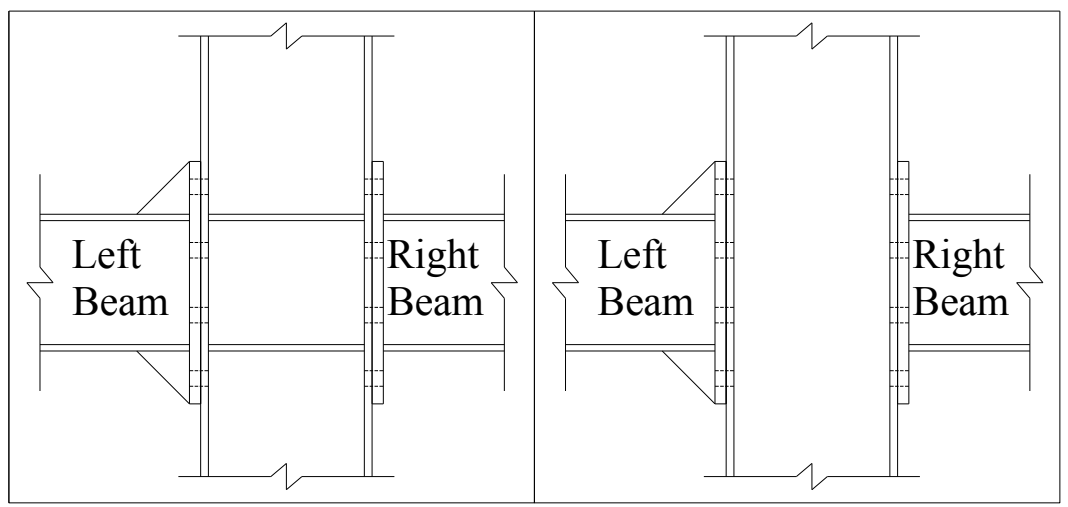

a) TS1 specimen

b) TS2 specimen

Fig. (1). Joint details: (a) TS1 specimen; (b) TS2 specimen.

Table 1. Main parameters of specimens (units: $\mathbf{m m}$ ).

\begin{tabular}{|c|c|c|c|c|c|c|c|}
\hline $\begin{array}{l}\text { Specimen } \\
\text { Number }\end{array}$ & $\begin{array}{c}\text { Column } \\
\text { Profile }\end{array}$ & $\begin{array}{l}\text { Beam } \\
\text { Length }\end{array}$ & $\begin{array}{l}\text { Beam } \\
\text { Profile }\end{array}$ & $\begin{array}{l}\text { End Plate } \\
\text { Thickness }\end{array}$ & $\begin{array}{l}\text { Beam } \\
\text { Length }\end{array}$ & $\begin{array}{c}\text { Bolt } \\
\text { Diameter }\end{array}$ & Remark \\
\hline TS1 & HM244x175x7x11 & 2000 & HM194x150x6x9 & 16 & 1000 & 20 & Internal joint \\
\hline TS2 & HM244x175x7x11 & 2000 & HM194x150x6x9 & 16 & 1000 & 20 & Internal joint \\
\hline
\end{tabular}

Table 2. Main material properties of the test specimens.

\begin{tabular}{|c|c|c|c|c|}
\hline Section B $\mathbf{x} \mathbf{H}\left(\mathbf{m m}^{2}\right)$ & Yield Strength $\boldsymbol{f}_{\mathbf{y}}(\mathbf{M P a})$ & Ultimate Strength $\boldsymbol{f}_{\boldsymbol{u}}(\mathbf{M P a})$ & Elastic Modulus $\boldsymbol{E}(\mathbf{G P a})$ & Elongation $\boldsymbol{\Delta} \boldsymbol{L} / \boldsymbol{L}(\boldsymbol{\%})$ \\
\hline \hline $6.3 \times 10$ & 263.5 & 466.9 & 204.8 & 22 \\
\hline $8.5 \times 10$ & 262.4 & 435.3 & 2196 & 22.7 \\
\hline $9.5 \times 9.9$ & 253.1 & 396.6 & 22 & 17.2 \\
\hline $10 \times 10.3$ & 263.1 & 445.6 & 206 & \\
\hline
\end{tabular}

tightened by the calibrated wrench method with bolt pretension forces of $155 \mathrm{kN}$ according to GB50017-2003 [9], because of the coupons obtained from different structural members, there was a certain dispersion of the elastic modulus, which was acceptable according to GB50017-2003.

\subsection{Test Setup}

The experiments were mainly focused on measuring initial stiffness, which is a reflection of the mechanical behavior of the panel zone. Two extended end-plate bare joints with various configurations were tested under monotonic loads (Figs. 2, 3).

The top and bottom ends of the column were fixed by the reaction frame and hydraulic jack, respectively. The load was placed axially on the column at a constant value of 325 $\mathrm{kN}$; the concentrated force was imposed simultaneously at each end of the steel beam by hydraulic jacks (Fig. 3). Tests were conducted under load control in the elastic phase and under displacement control after the plastic phase reached until failure occurred. Pressure sensor and displacement sensor were placed at the load-end of the beam. The relative rotation of the panel zone could be calculated by the measured displacement and load. The main components of a test included: (1) the vertical load force of the beam end; (2) the vertical displacement of the beam end; (3) the strain of the panel zone; (4) the rotation of the panel zone; and (5) the failure process of the joint.

\section{FINITE ELEMENT MODEL}

Corresponding simulations were performed using the finite element analysis software ABAQUS, and a comparison between the numerical and experimental results is presented. The multilinear isotropic hardening model was adopted for beams, columns, and end plates, while the bilinear isotropic hardening model was adopted for bolts. The von Mises yield criterion and associated flow rule were also applied. The constitutive model of steel obtained from the tests is shown in Table 2 . The constitutive model of bolts applied in this paper was defined based on reference [10] and is shown in Table 3. The finite element analysis was carried out under load control, where the maximum loading was considered to be the same as that of the experimental results.

\subsection{Method 1: Three-Dimensional Solid Model}

Linear solid elements (C3D8R) were adopted in the modeling. The size of the finite element model of the beam, column, and bolts is in complete accord with experimental specimens. In addition, the magnitudes of the bolt pre- 


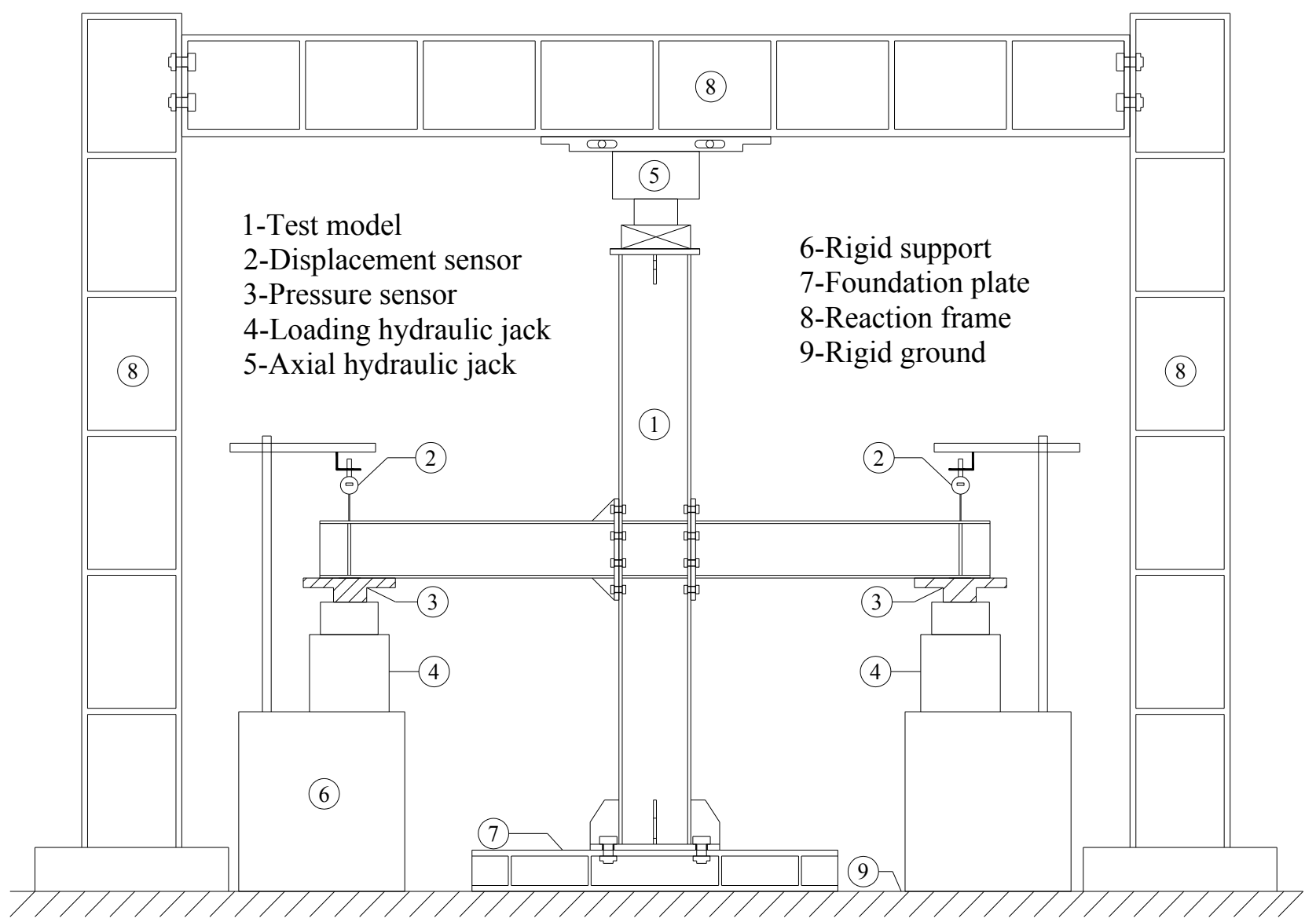

Fig. (2). Test apparatus for internal joint under symmetrical monotonic loading.
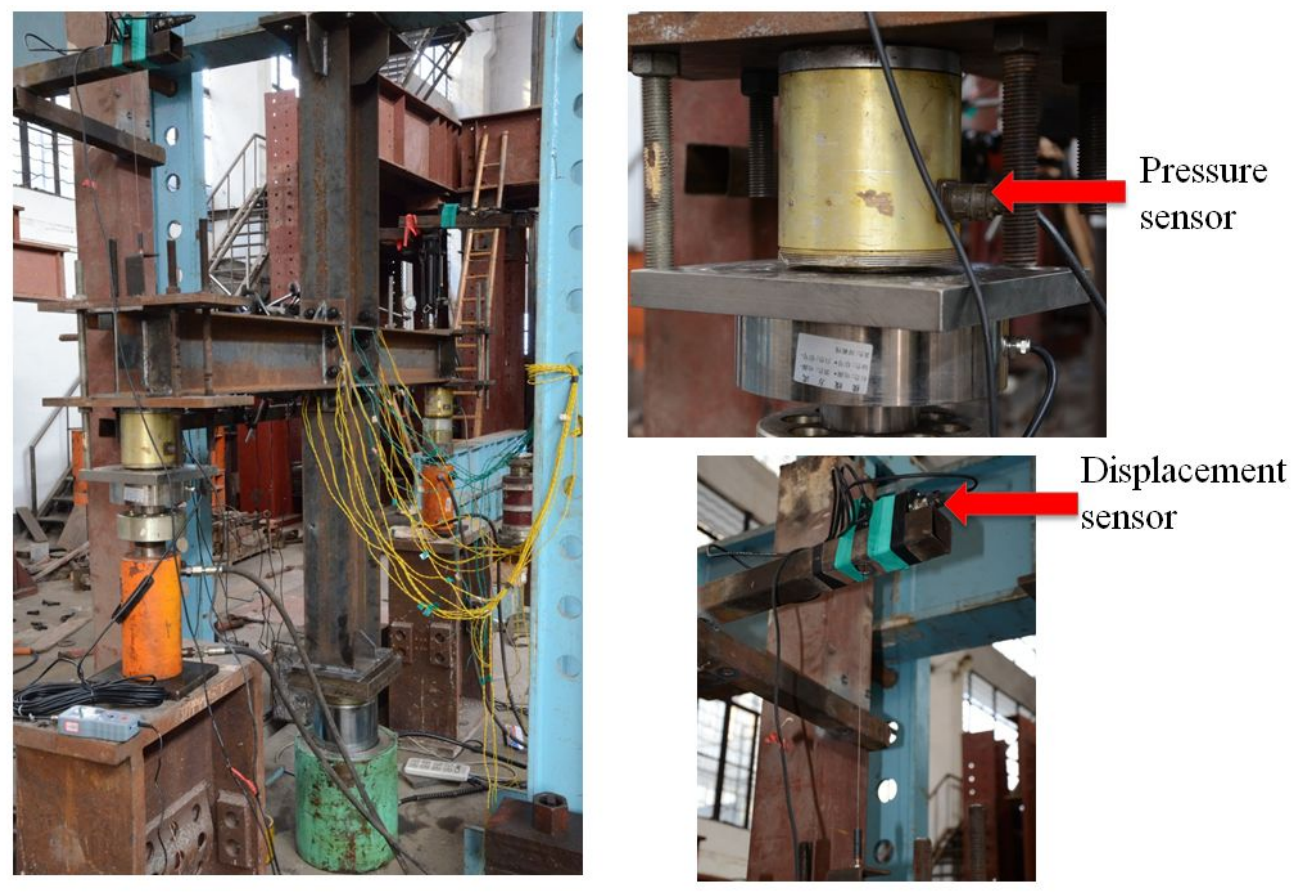

Fig. (3). Arrengement of pressure sensor and displacement sensor.

tension forces and column axial force along with the loading sequence and loading orientation were also consistent with those of experiments. In order to ensure the accuracy and to simplify the calculation, different mesh sizes were adopted.
The approximate mesh size of the panel zone was $5 \mathrm{~mm}$, while the size of the remaining part of the model was $20 \mathrm{~mm}$ (Fig. 4). 
Table 3. Properties of high-strength bolts.

\begin{tabular}{|c|c|c|c|c|}
\hline Material & Yield Strength $\boldsymbol{f}_{\boldsymbol{y}}(\mathbf{M P a})$ & Ultimate Strength $\boldsymbol{f}_{\boldsymbol{u}}(\mathbf{M P a})$ & Yield Strain $\boldsymbol{\varepsilon}_{\boldsymbol{y}}(\%)$ & Ultimate Strain $\varepsilon_{\boldsymbol{u}}(\%)$ \\
\hline \hline High strength bolt & 940 & 1130 & 0.456 & 10 \\
\hline
\end{tabular}

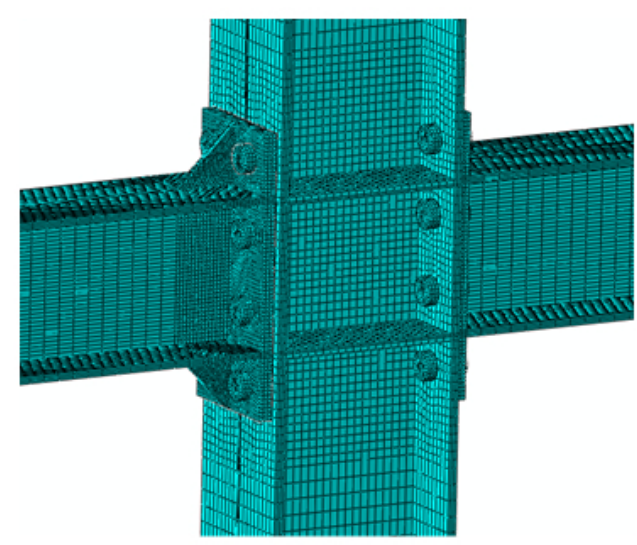

a) Finite element model of TS1

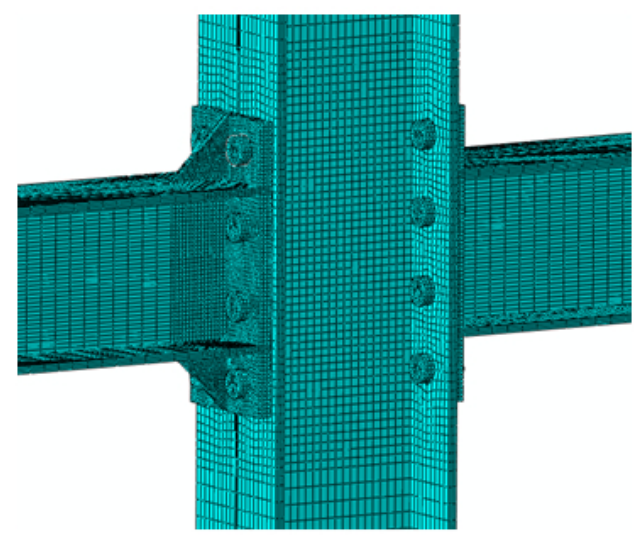

b) Finite element model of TS2

Fig. (4). Three-dimension FEM Model: (a) Finite element model of TS1; (b) Finite element model of TS2.

\subsection{Method 2: Shell Model Combined with Spring Representation of Joint Components}

The SPRING element, which can effectively simulate the axial mechanical behavior between two points, was adopted for modeling each mechanical component. Shell elements (S4R) were adopted to simplify the components of the beam. The initial stiffness values of each component are discussed in the following paragraphs. In order to clearly understand the mechanical impact of extended end-plate stiffeners, two simplified models were built: one with an extended end-plate

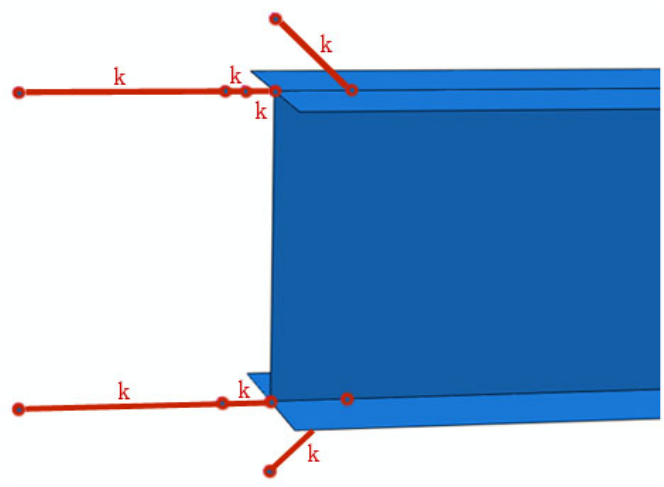

a) Spring element model of left beam stiffener spring and a second without an end-plate stiffener spring (Fig. 5).

\subsection{Spring Stiffness Determination of the Mechanical Components}

Gao et al. [11] pointed out that the mechanical components (such as the column flange in bending, the column web panel in shear, the column web in compression, the end-plate in bending, the column web in tension and the bolts in tension) should be considered to build the spring

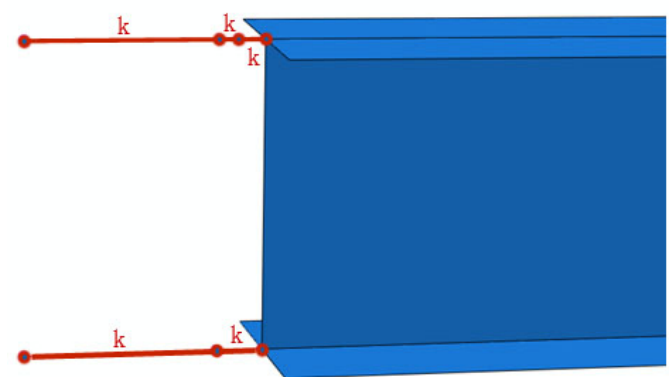

b) Spring element model of right beam

Follow the line of action between two points

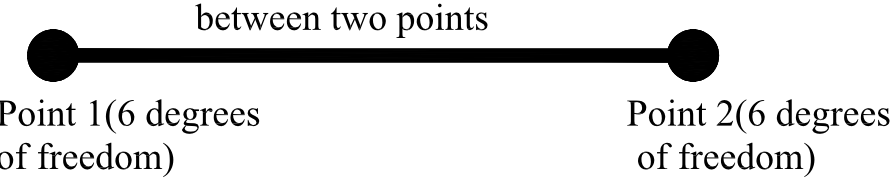

c) Connect-two-points spring element

Fig. (5). Spring model based on component method: (a) Spring element mldel of left beam; (b) Spring element model of right beam;(c) Connect-two-points spring element. 


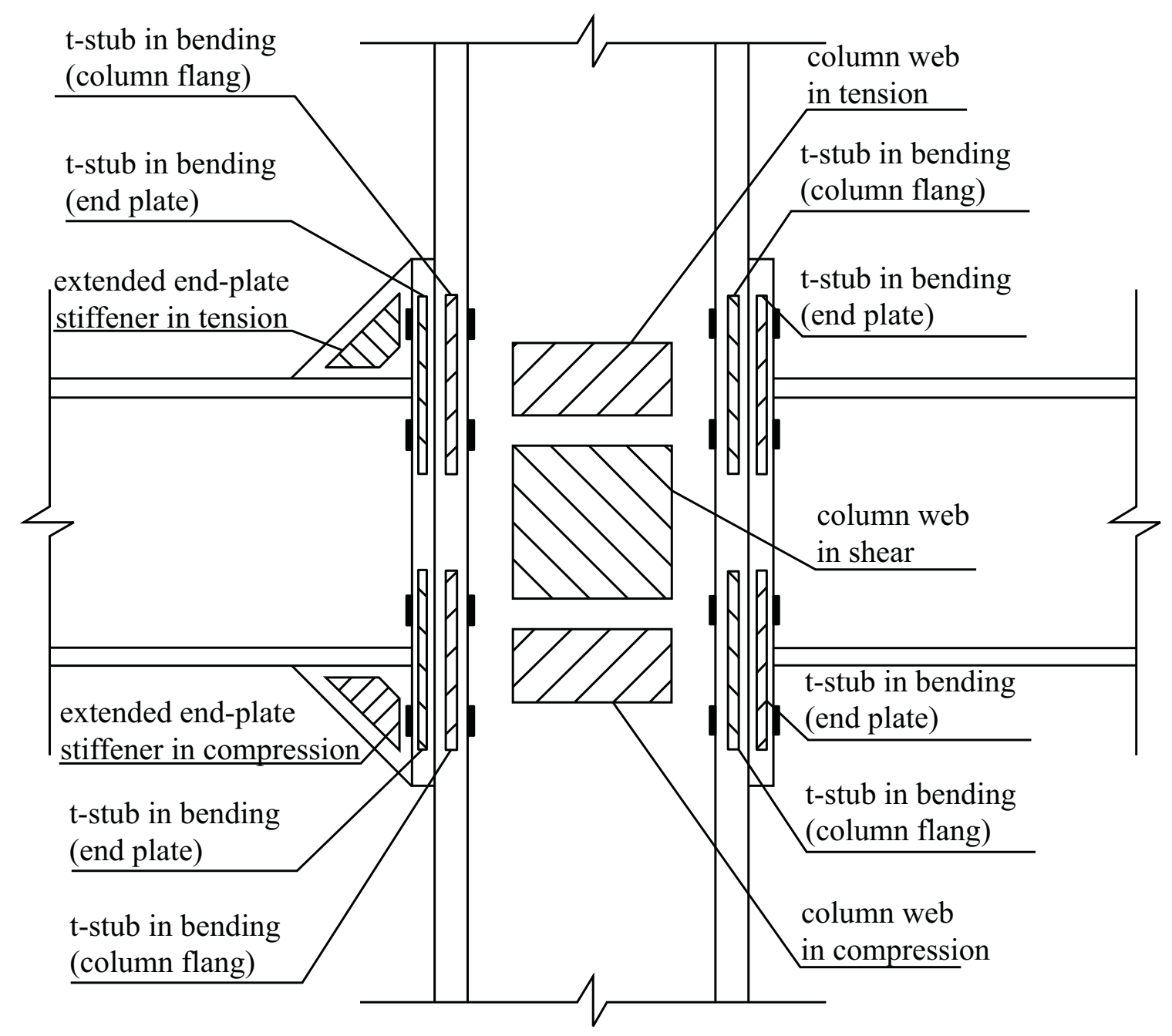

Fig. (6). Components of extended end-plate connection.

model. When calculating the initial rotational stiffness, the components of the beam (the beam flange in compression and tension and the beam web in compression and tension) also needs to be considered. However, the Eurocode indicates that the components of the beam with infinite stiffness have little influence on the deformation of the connections; therefore, its contribution to the initial stiffness of the joint can be ignored. Fig. (6) shows the components of the extended end-plate connection in detail.

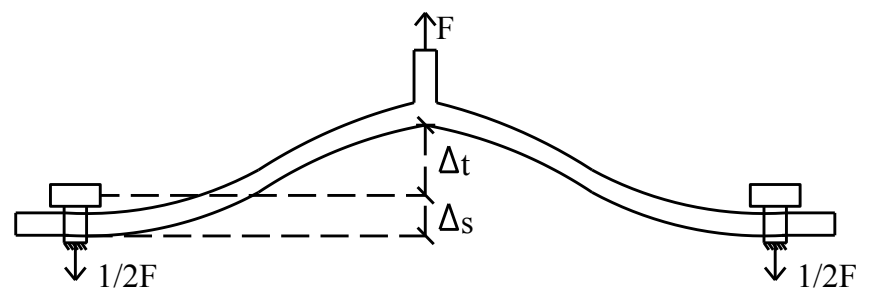

Fig. (7). Calculation model of T-stub.

When a load is applied to the extended end-plate connection, the stress states of the column flange and extended end-plate are assumed to be pure bending, and these components are considered to act as T-stub. The global deformation of T-stub contains two parts $\left(\Delta_{t}\right.$ and $\Delta_{s}$; Fig. 7);
$\Delta_{\mathrm{t}}$ represents the bending deformation of the flange slab and the bolt, while the combined axial deformation of bolt in tension and flange slab in compression is represented by $\Delta_{\mathrm{s}}$.

In order to simplify the calculation, the flange slab was considered from one side of the support to mid-span, and a symmetry constraint was also applied (Fig. 8a). Thus, the bending moments are as follows:

$$
\begin{aligned}
& M_{12}=\frac{F}{2} \cdot m \cdot \frac{1+2 \gamma}{1+4 \gamma} \\
& M_{21}=\frac{F}{2} \cdot m \cdot \frac{2 \gamma}{1+4 \gamma} \\
& \gamma=0.589 \cdot \frac{m}{h_{b o l t}} \cdot \frac{d_{b o l t}^{4}}{b_{e f f} t_{f}^{3}}
\end{aligned}
$$

The deformation caused by the bending of the flange slab and bolt can be calculated using the diagrammatic multiplication method:

$$
\Delta_{t}=\frac{1}{E I} \cdot \frac{l^{2}}{8} \cdot\left(\frac{2}{3} M_{12}-\frac{1}{2} M_{21}\right)
$$




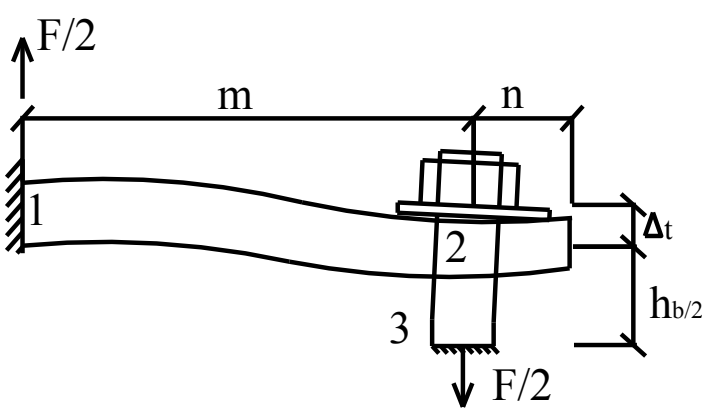

a) Flange slab and bolt in bending

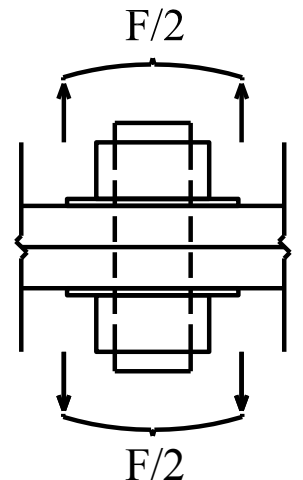

b) Flange slab in compression and bolt in tension

Fig. (8). Simplified calculation model: (a) Flange slab and bolt in bending; (b) Flange slab in compression and bolt in tension.

Fig. (8b) shows the combined axial deformation of bolt in tension and flange slab in compression, as described by Wang [12]:

$K_{s}=\frac{2 n \lambda K_{b}}{3 \ln \left|\frac{3+3 \lambda}{3+\lambda}\right|}$

$\lambda=5.7+2.95 t_{f} / d_{b o l t}$

$\Delta_{s}=\frac{1 / 2 F}{K_{s}}$

The initial stiffness of the spring simulating the T-stub may be determined as follows:

$$
K_{t-\text { stub }}=\frac{F}{\Delta_{t}+\Delta_{s}}=\frac{1}{\frac{3 \ln \left|\frac{3+3 \lambda \mid}{3+\lambda}\right|}{4 n \lambda K_{b}}+\frac{1}{48} \cdot \frac{l^{3}}{E I} \cdot \frac{1+\gamma}{1+4 \gamma}}
$$

where:

$t_{f}$ - the thickness of the T-stub flange;

$b_{\text {eff }}$ - the effective span of the T-stub;

$E$ - the elastic modulus of the T-stub;

$h_{\text {bolt }}, d_{\text {bolt }}$ - the effective bending length and diameter of bolt, respectively; and
$K_{b}$ - the initial tensile stiffness of bolt.

The stiffness of the column web in tension or compression is evaluated by Eq. (9) [11]:

$K_{c w}=\frac{E_{c w} t_{c w} b_{e f f, c w}}{h_{c w}\left(1-v^{2}\right)}$

where:

$E_{c w}$ - the elastic modulus of the column web;

$t_{c w}$ - the thickness of the column web;

$b_{\text {eff,cw }}$ - the effective width of the column web in tension (compression);

$h_{c w}$ - the height of the column web; and

$v$ - the Poisson ratio of the column web.

The shear stiffness of the column web is evaluated by Eq. (10) [11]:

$K_{v, c w}=0.365 \frac{E_{c w} A_{v, c w}}{\beta z_{v, c w}}$

where

$A_{v, c w}$ - the effective shear area of the column web;

$\beta$ - the parameter for the shear number of the edge; and

$Z_{v, c w}$ - the height of the effective shear area.

Table 4. Initial stiffness values of components (unit: $\mathrm{kN} / \mathrm{mm}$ ).

\begin{tabular}{|c|c|c|c|c|}
\hline Components & Stiffened & Unstiffened & Stiffened & Unstiffened \\
\hline Column web in compression & 2007970 & 2007970 & 613367 & 61367 \\
\hline T-stub in bending(column flange) & 1728714 & 1728714 & 1728714 & 1728714 \\
\hline Stiffener in tension & 1040000 & 0 & 1040000 & 0 \\
\hline Stiffener in compression & 1040000 & 0 & 1040000 & 0 \\
\hline
\end{tabular}




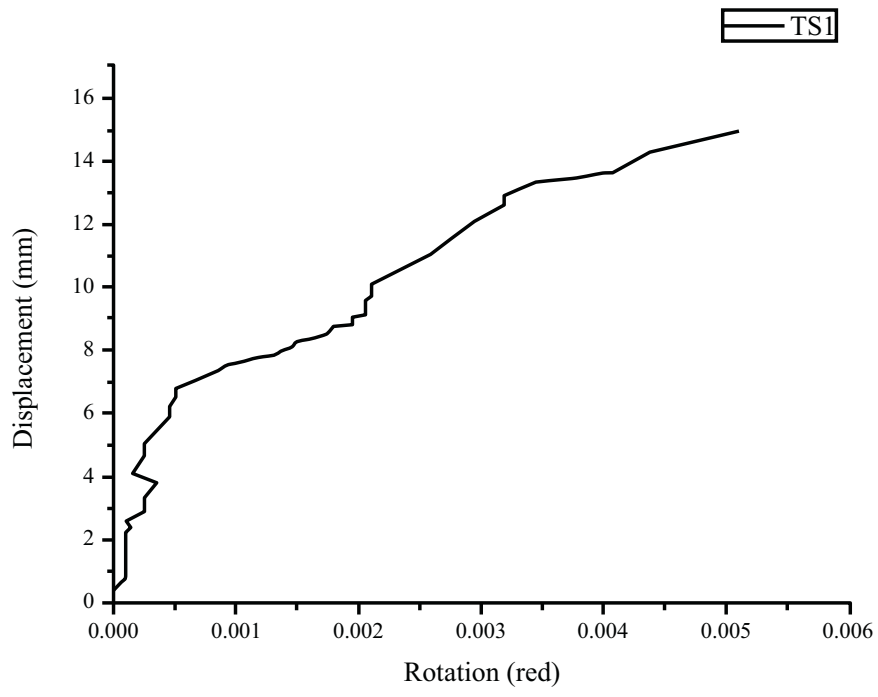

a) TS1 specimen

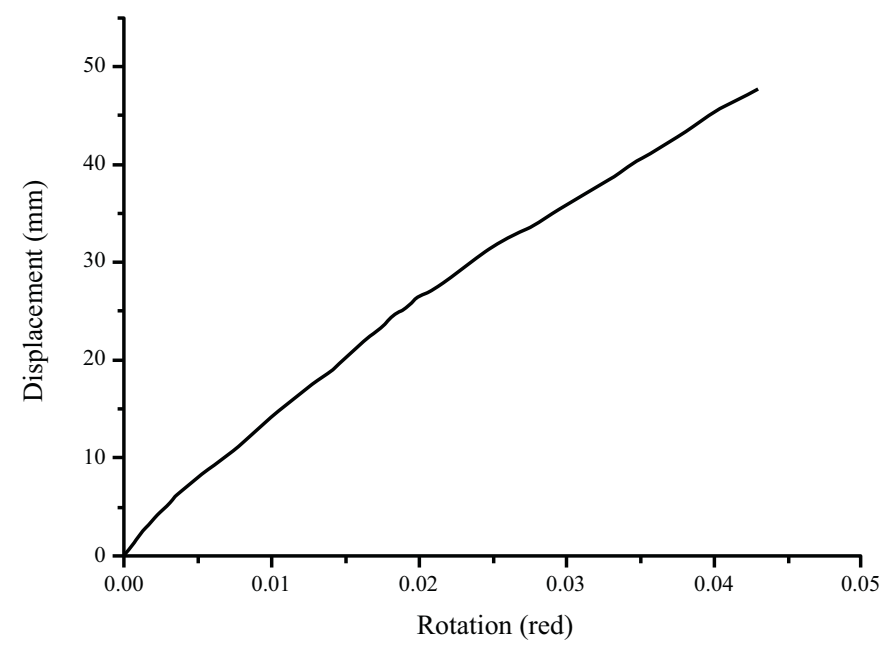

b) TS2 specimen

Fig. (9). Rotation-displacement curves: (a) TS1 specimen; (b) TS2 specimen.

The initial stiffness values of the mechanical components for TS1 and TS2 were calculated and are listed in Table 4. These values served as input parameters for the SPRING element and were involved in the numerical calculation based on method 2 .

\section{COMPARISON BETWEEN TEST RESULT AND FEM ANALYSIS}

\subsection{Analysis of Rotation-Displacement Characteristics}

Fig. (9) illustrates the relationship between the loading displacement and the rotation of the panel zone. The relationship between the loading displacement and the strain of the end-plate stiffener is shown in Fig. (10). The column stiffeners had a significant effect on the overall deformation of the joint. Under the influence of the stiffeners, the displacement at the load end of the beam was not completely proportional to the rotation of the panel zone [13]. The bending deflection of the beam also contributed to the rotation of the panel zone in addition to the beam displacement, and the influence of the plastic rotation should be considered in the plastic phase. The moment-rotation relationship before and after the appearance of the plastic hinge of the beam are given by Eqs. (11) and (12):

$$
\begin{aligned}
& s=\theta_{1} L+\frac{M_{\text {beam }} L^{2}}{3 E_{\text {beam }} I} \\
& s=\theta_{1} L+\frac{M_{\text {beam }} L^{2}}{3 E_{\text {beam }} I}+\theta_{2} L
\end{aligned}
$$

where:

$s$ - the displacement at loading end of the beam;

$\theta_{1}$ - the relative rotation of the joint;

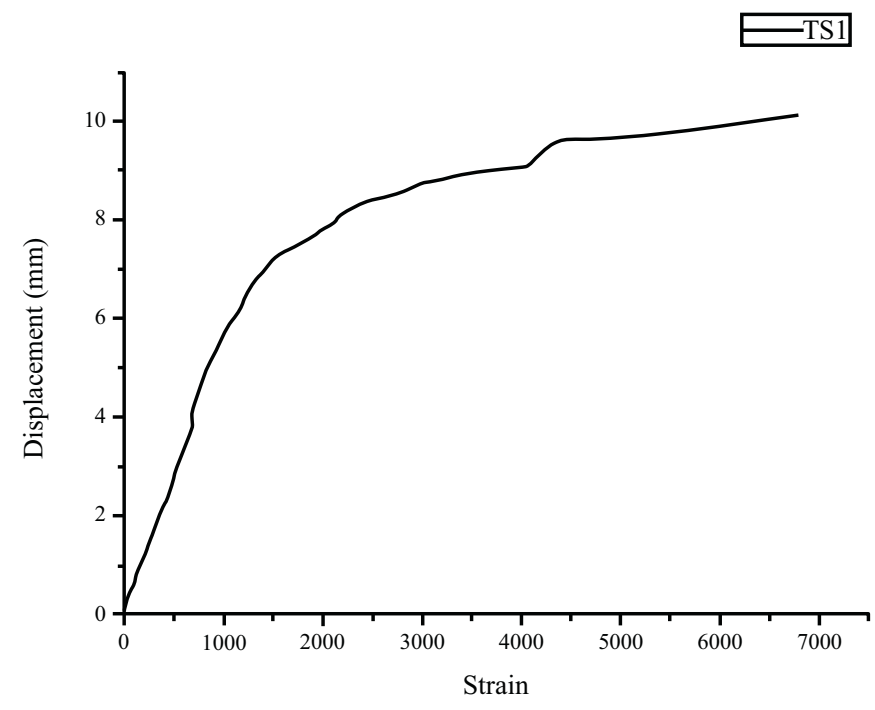

a) TS1 specimen

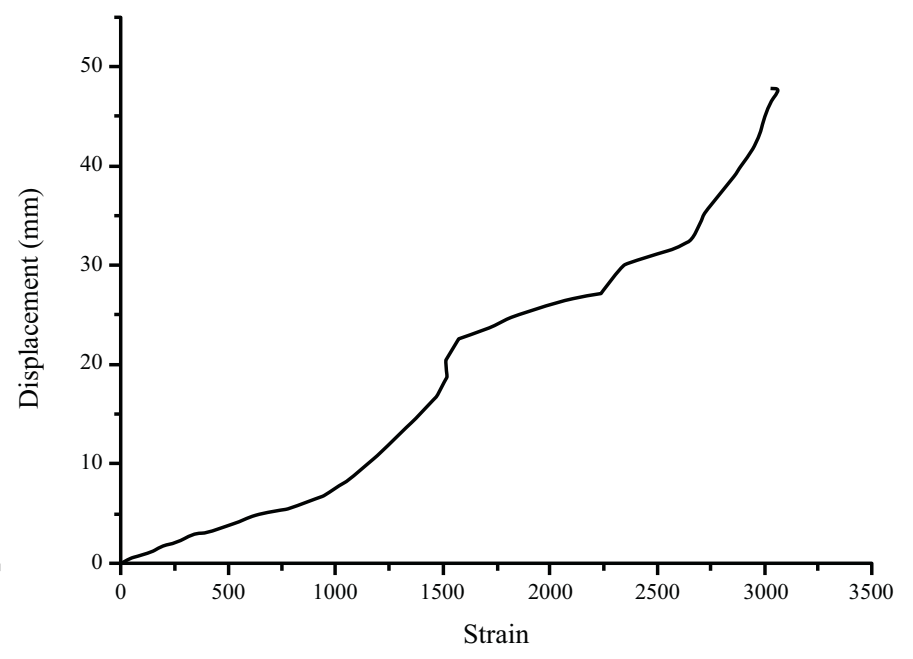

b) TS2 specimen

Fig. (10). Strain-displacement curves: (a) TS1 specimen; (b) TS2 specimen. 
$\theta_{2}$ - the plastic hinge rotation of the beam;

$M_{\text {beam }}$ - the bending moment of the beam;

$L$ - the distance between the loading application point and the face of the end plate;

$E_{\text {beam }}$ - the elastic modulus of the beam; and

$I$ - the moment of inertia

\subsection{The Behavior of the Connection Under Monotonic Loading}

Fig. (11) shows the complete rotational behavior obtained from the experiments on each of the tested joints, where $M$ is the bending moment acting on the connection, and $\theta$ is the rotation of the joint calculated by Eqs. (11) and (12). A comparison of the experimental curves shows that both stiffness and resistance increased significantly when the connection had extended end-plate stiffeners. The local stability of the joint TS1 was enhanced due to the column stiffener. The moment resistance of the joint also exhibited an increasing trend. The ultimate failure in TS1 was defined based on when the loading displacement exceeding the safety limit of the structure. The local stability of TS2 was poor, and the moment resistance of the joint exhibited a decreasing trend due to the local bucking that occurred in the web of the column.

Fig. (12) shows the experimental results of the failure mode testing. The deformation of the panel zone in specimen TS1, which was derived from the local bucking in the beam flange, was not large due to the enhancement of the column

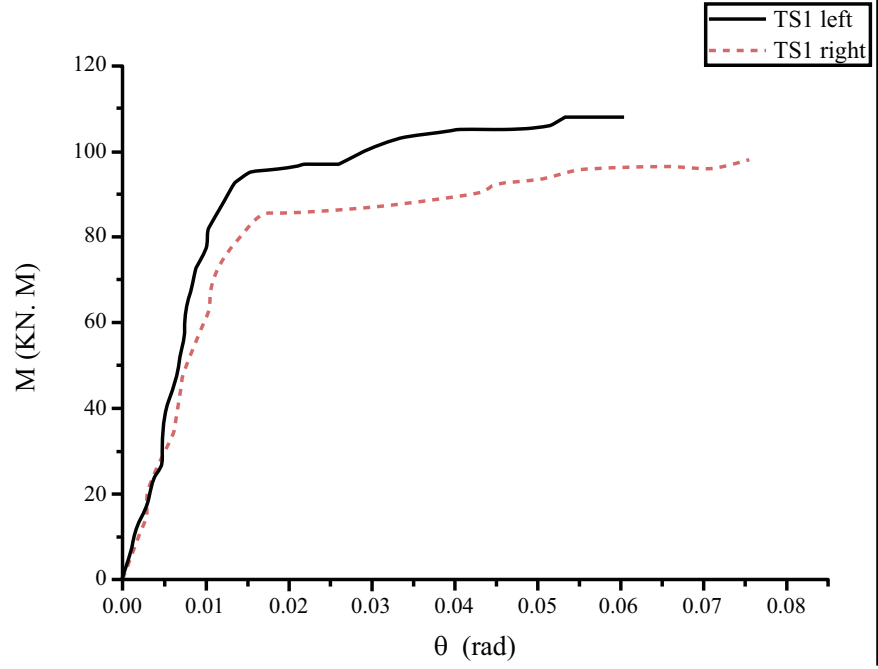

a) TS1 specimen, left and right connections

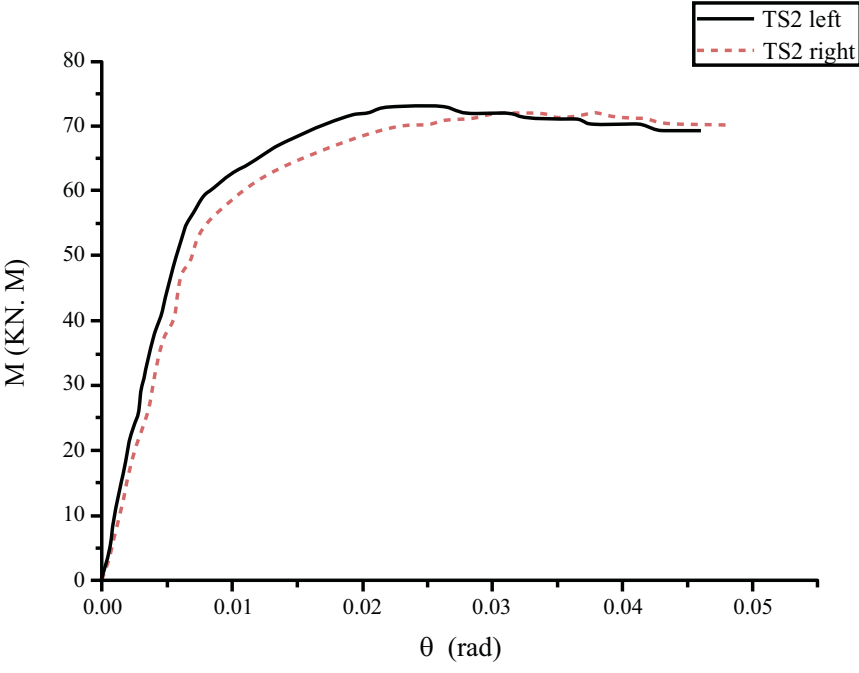

b) TS2 specimen, left and right connections

Fig. (11). Resulting moment-rotation behavior for the tested joints: (a) TS1 specimen, left and right connections; (b) TS2 specimen, left and right connections.
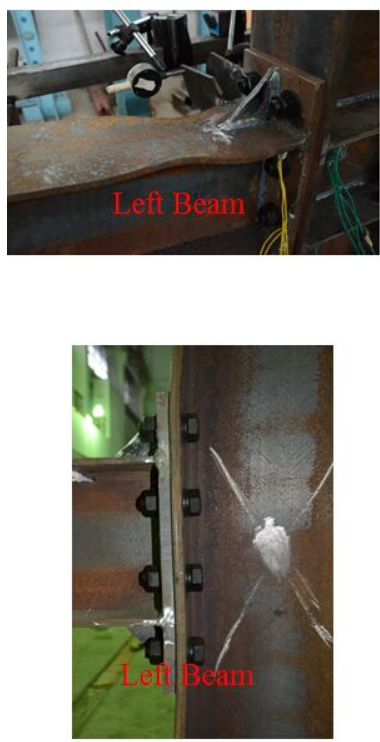

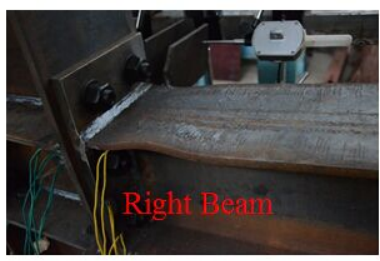

(a) Failure model of TS1
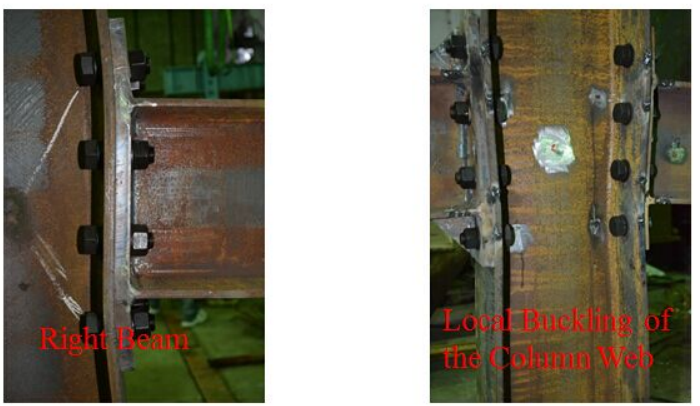

(b) Failure model of TS2

Fig. (12). Test result: (a) Failure model of TS1; (b) Failure model of TS2. 


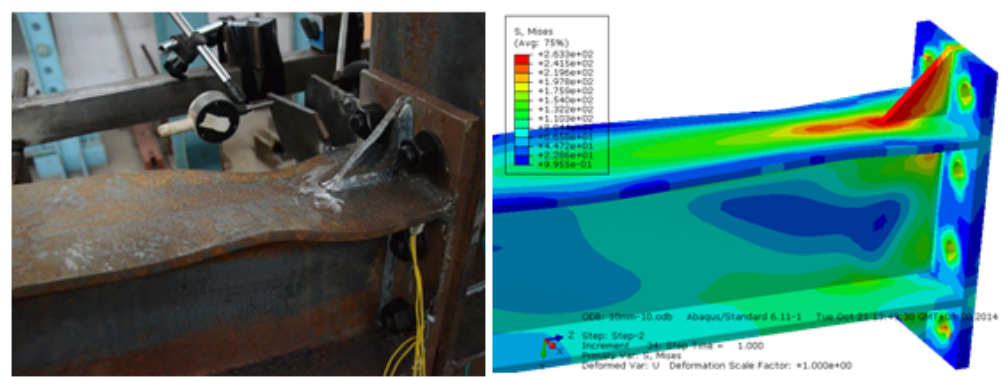

a) Left beam
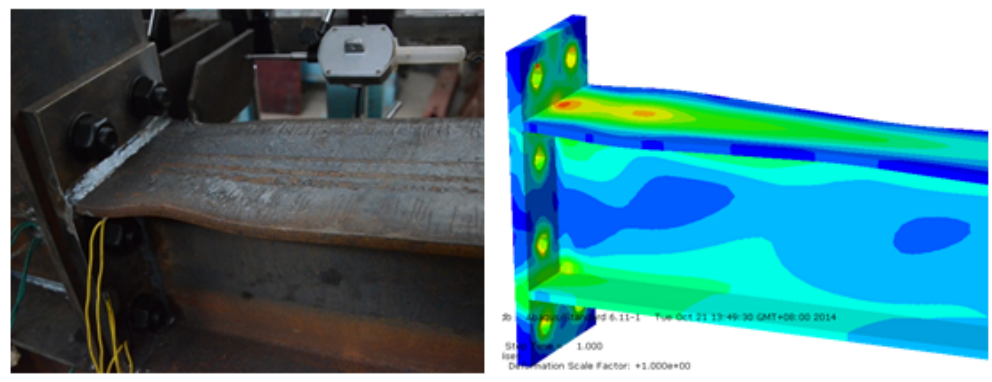

b) Right beam

Fig. (13). Comparison between experiment and finite element analysis: (a) Left beam; (b) Right beam.

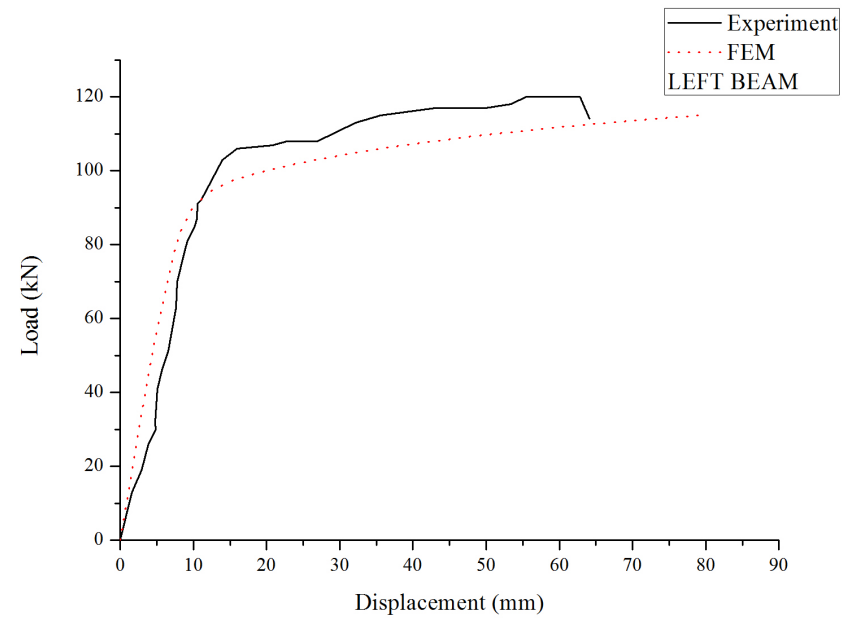

a) Correlation curves of left beam

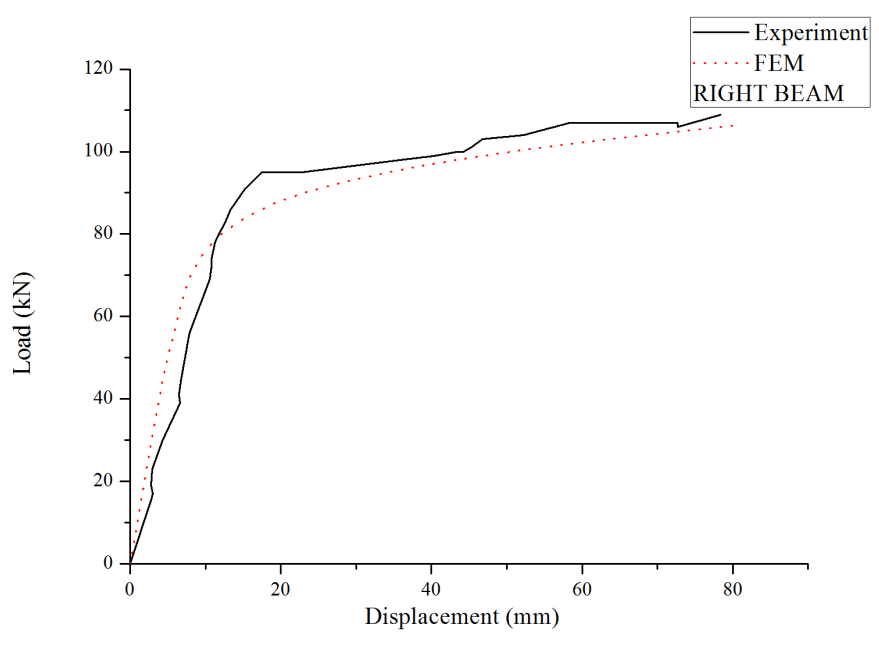

b) Correlation curves of right beam

Fig. (14). Load-displacement curves for TS1: (a) Correlation curves of left beam; (b) Correlation curves of right beam.

stiffener. The plastic hinge of the left joint moved outside due to the setting up of the extended end-plate stiffeners. An obvious slip line in the beam web was observed, which accounts for the tendency to shear failure. The deformation of the end plate of sample TS2 was in accordance with the column flange. The local bucking of the column web resulted from main deformation of the panel zone and the decreased moment resistance.

\subsection{Mechanical Analysis of the End-Plate Stiffener Based on Method 1}

Fig. (13) shows the ultimate deformation between experiment and finite element analysis, and the loaddeformation curves for TS1 are illustrated in Fig. (14). Compared with the experimental results, three-dimensional

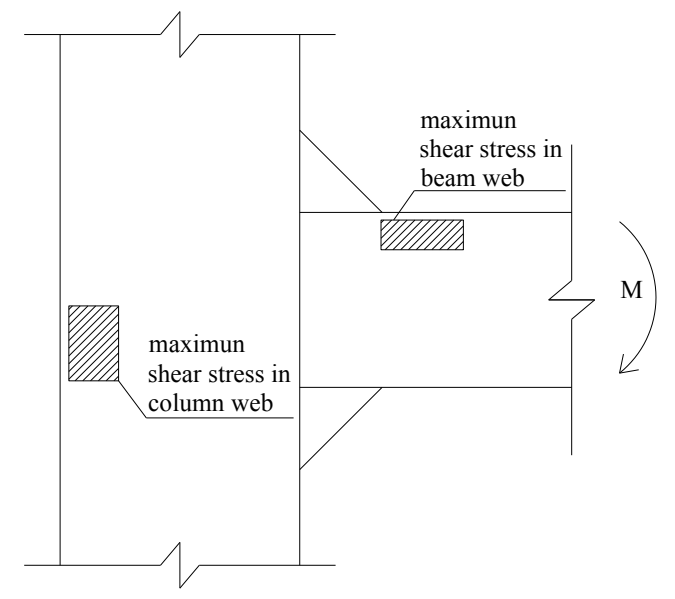

Fig. (15). Location of maximum shear stress in column web and beam web. 
modeling can effectively simulate the plastic development and deformation characteristics of the specimen throughout the entire loading process and provide more consistent data. Thus, this method is accurate and feasible to describe the stress distribution in the mechanical components of the specimen. Accordingly, this numerical method was employed to investigate the influence of different stiffener parameters on the initial rotational stiffness of internal joints.

References [14] and [15] suggested that the optimal bevel angle and length-to-height ratio of the stiffener are $63^{\circ}$ and $2: 1$, respectively. In this study, stiffeners with four different

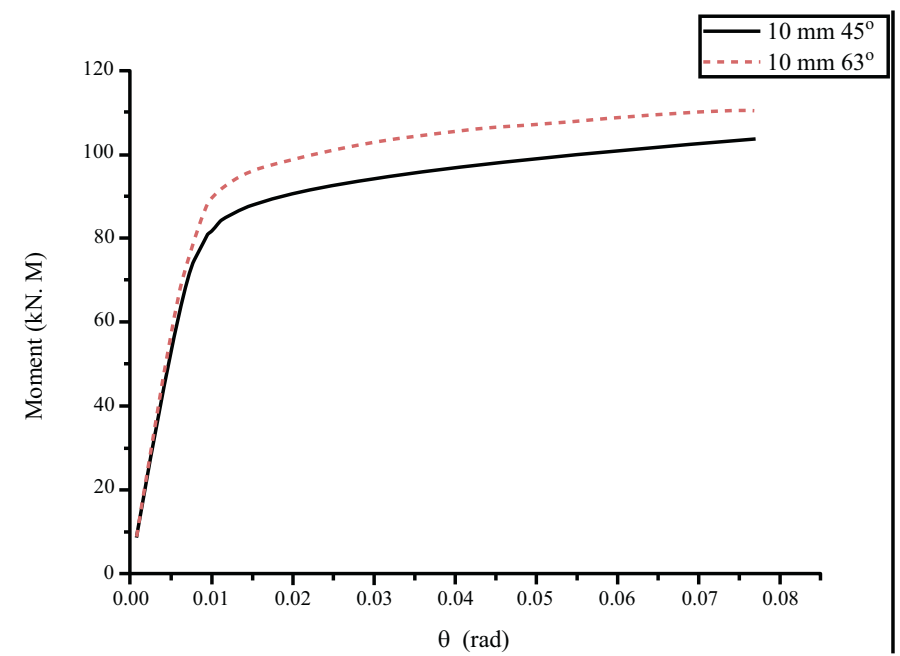

a) $10 \mathrm{~mm}$ stiffeners with angles of $45^{\circ}$ and $60^{\circ}$

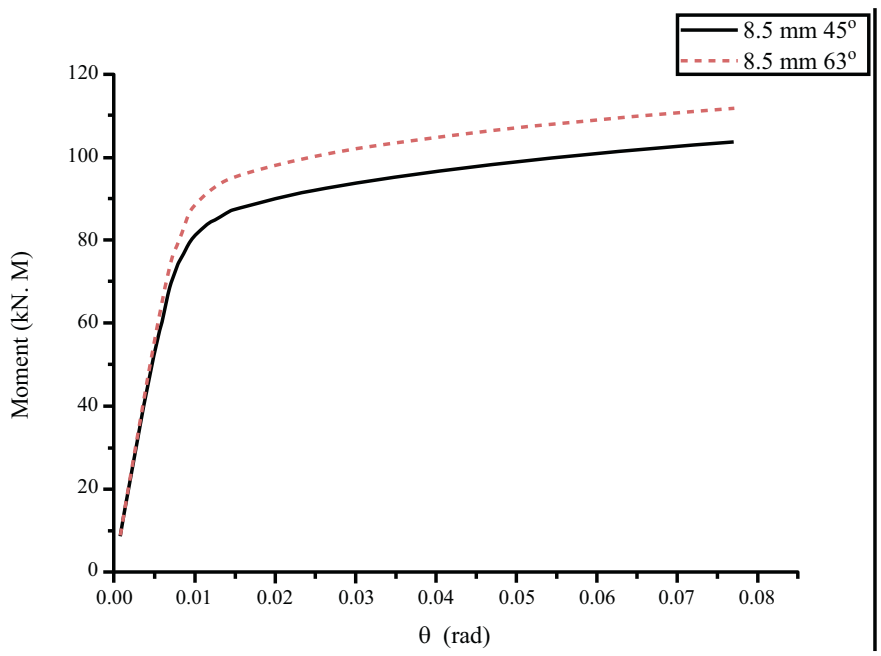

c) $8.5 \mathrm{~mm}$ stiffeners with angles of $45^{\circ}$ and $60^{\circ}$ thicknesses were adopted: $6 \mathrm{~mm}$ (web thickness), $10 \mathrm{~mm}$ (experimental model value), $8.5 \mathrm{~mm}$, and $14 \mathrm{~mm}$ (values proposed by reference [16]). In order to simplify the analysis and calculation, external joint models under hogging moment were adopted. Fig. (15) shows the location of maximum shear stress in column web and beam web under hogging moment.

Table 5 presents the shear transfer efficiencies resulting from the different stiffener thicknesses. The maximum shear stress of the column area is more sensitive to changes in stiffener thickness than the maximum shear stress of the

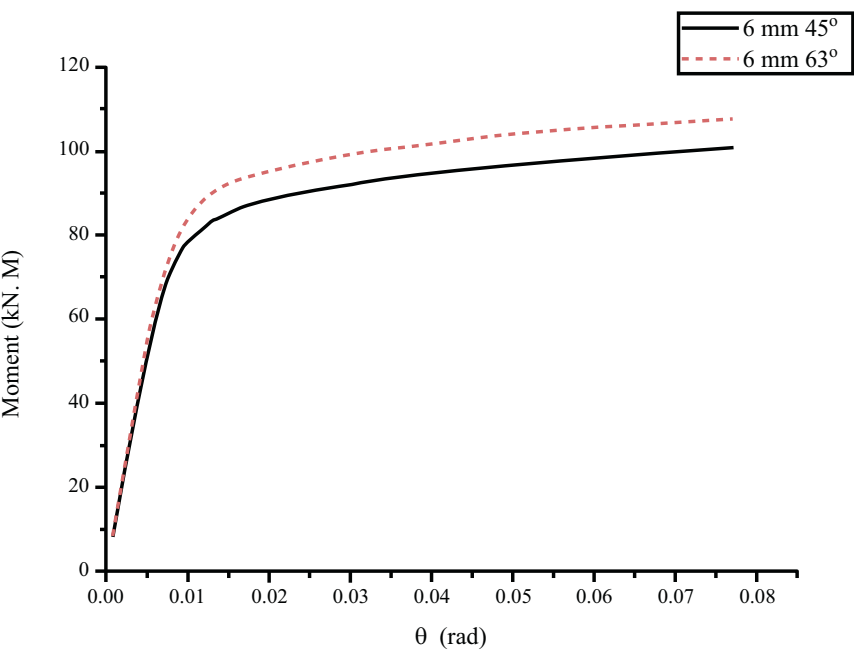

b) $6 \mathrm{~mm}$ stiffeners with angles of $45^{\circ}$ and $60^{\circ}$

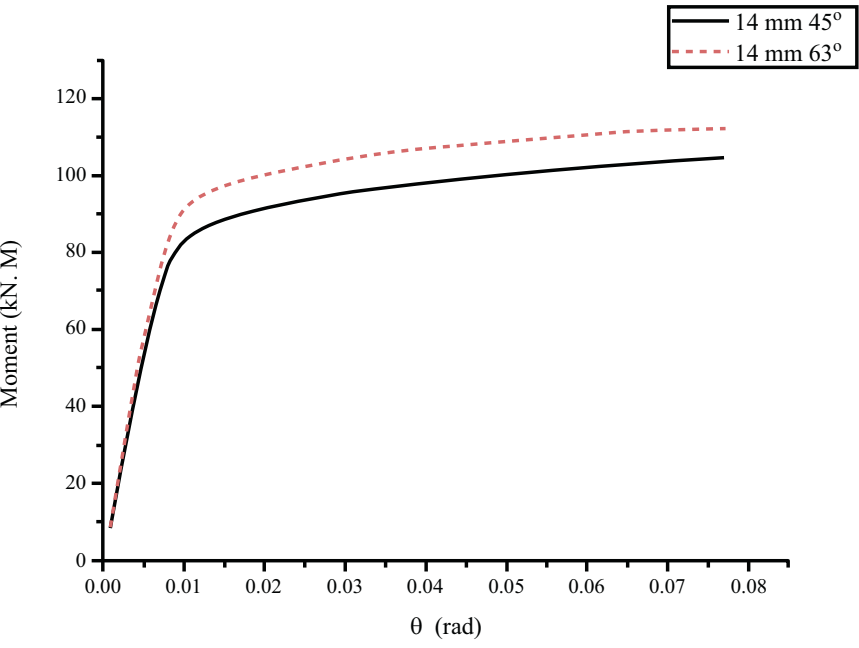

d) $14 \mathrm{~mm}$ stiffeners with angles of $45^{\circ}$ and $60^{\circ}$

Fig. (16). Moment-rotation curves under the influence of angle: (a) $10 \mathrm{~mm}$ stiffeners with angles of $45^{\circ}$ and $60^{\circ}$; (b) 6 mm stiffeners with angles of $45^{\circ}$ and $60^{\circ}$; (c) $8.5 \mathrm{~mm}$ stiffeners with angles of $45^{\circ}$ and $60^{\circ}$; (d) $14 \mathrm{~mm}$ stiffeners with angles of $45^{\circ}$ and $60^{\circ}$.

Table 5. Efficiency of shear transfer for different stiffener thicknesses.

\begin{tabular}{|c|c|c|c|}
\hline Thickness & $\begin{array}{c}\text { Maximum Shear Stress in } \\
\text { Column (Mpa) }\end{array}$ & $\begin{array}{c}\text { Maximum Shear Stress in Beam } \\
\text { (Mpa) }\end{array}$ & Efficiency \\
\hline \hline $6 \mathrm{~mm}$ & 165.4 & 147.6 & $89.2 \%$ \\
\hline $8.5 \mathrm{~mm}$ & 164.2 & 146.3 & $89 \%$ \\
\hline $10 \mathrm{~mm}$ & 168.3 & 146.9 & $87.3 \%$ \\
\hline $14 \mathrm{~mm}$ & 171 & 146.3 & $85.5 \%$ \\
\hline
\end{tabular}




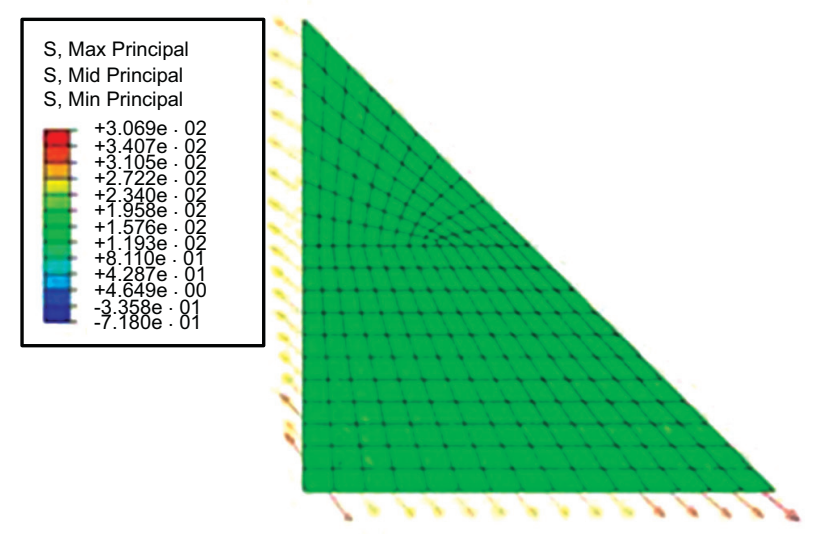

Principal stress orientation in tension
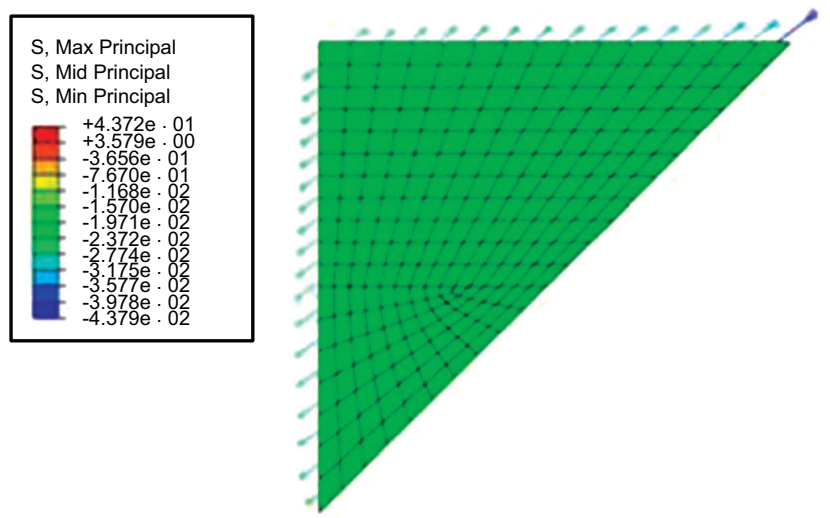

Principal stress orientation in compression
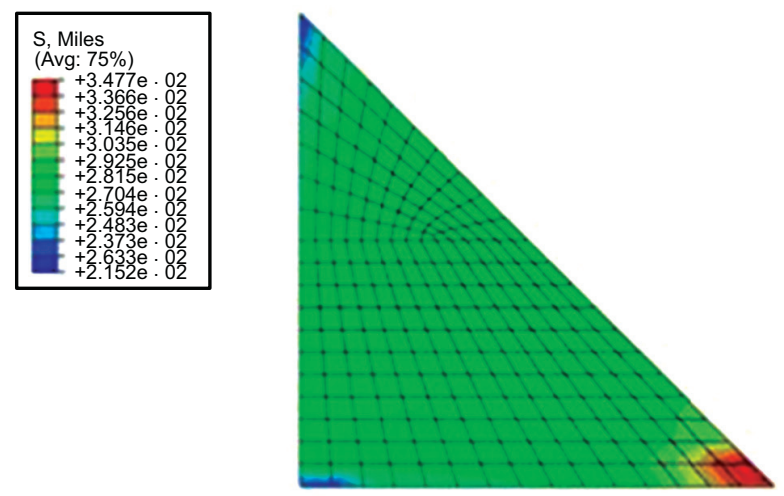

In-plane stress nephogram in tension
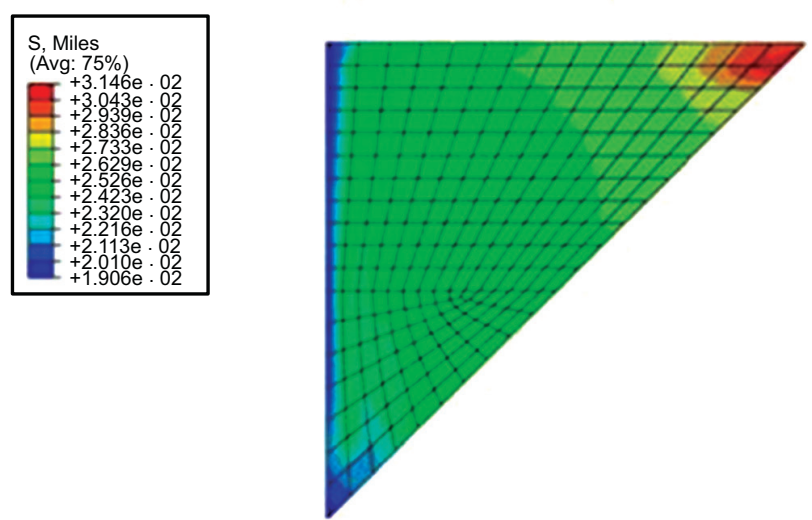

In-plane stress nephogram in compression

Fig. (17). Principal stress direction and in-plane stress nephogram for stiffener: (a) Principal stress orientation in tension;(b) In-plane stress nephogram in tension; (c) Principal stress orientation in compression; (d) In-plane stress nephogram in compression.

beam region. With increasing stiffener thickness, the shear transfer efficiency of the panel zone decreases, and the shear transfer efficiency is maximized when the thickness of the stiffener is equal to the web thickness $(6 \mathrm{~mm})$. Fig. (16) shows the moment rotation curves of the joints for different stiffener angles. As the stiffener angle changes from $45^{\circ}$ to $63^{\circ}$, the shear transfer path from the panel zone to the beam also changes, resulting in improvements of the initial rotational stiffness and bearing capacity.

Fig. (17) shows that the principle stress is distributed equally along the leg in the direction parallel to the hypotenuse. The in-plane stress distribution was uniform accounting for total cross-section works together. The mechanical model of initial tensile stiffness of the stiffener is given in Fig. (18).

Fig. (18) shows the mechanical model of the extended end-plate stiffener. The stress flow of the stiffening plate is along the $\mathrm{x}$-axis; thus, an integrative approach along the $\mathrm{x}$ axis can be used to calculate the tensile stiffness of the stiffening plate as follows:

$K_{\text {stiffener }}=\frac{E_{s} t_{s}}{\tan \theta+\cot \theta}$

where: $t_{s}$ - the thickness of the extended end-plate stiffener;

$\theta$ - the angle of the extended end-plate stiffener (Fig. 18); and

$E_{s}$ - the elastic modulus of the extended end-plate stiffener.

\subsection{Initial Stiffness Analysis}

The initial stiffness values obtained from the two numerical models and the experimental results are compared in Table 6. According to the experiment result in elastic phase, the values of displacement and load at the load-end of the beam from the two numerical models were extracted. The initial stiffness would be the linear slope of the $M-\theta$ curve which was calculate by Eq.(11). Compared with the experiment, results of both FEM methods are acceptable. The initial joint rotational stiffness obtained from FEM (method 1) is more consistent with experiment because of the accurate three-dimensional modeling, and the relative error is controlled within $10 \%$. The calculation error obtained by FEM (method 2) is a little bigger because the components and constraints are simplified, while the advantage of this method is preprocessing and calculations are easy. Compared with the beam end without extended 
Table 6. Initial stiffness values of test specimens (unit: $\mathrm{kN} \cdot \mathrm{m} / \mathrm{rad}$ ).

\begin{tabular}{|c|c|c|c|c|}
\hline Data Source & \multicolumn{2}{|c|}{ TS1 } & \multicolumn{2}{|c|}{ TS2 } \\
\hline \multirow{2}{*}{$\begin{array}{c}\text { FEM (method 1) } \\
\text { Compared with Experiment }\end{array}$} & 12641 & 10726 & 9044.9 & 7804.2 \\
\hline & $-8.4 \%$ & $-1.8 \%$ & $1.1 \%$ & $6.7 \%$ \\
\hline $\begin{array}{c}\text { FEM (method 2) } \\
\text { Compared with Experiment }\end{array}$ & $-13.8 \%$ & $-7.2 \%$ & $5.6 \%$ & $-2.7 \%$ \\
\hline
\end{tabular}

end-plate stiffeners, the beam ends with the extended endplate stiffeners exhibit approximately $20 \%$ and increases in initial rotational stiffness. The stiffnesses of the joints with extended end-plate stiffeners are clearly increased, mainly due to the upper stiffener in tension and the lower stiffener in compression. The application of Eq. (13) in method 2 makes the numerical results more consistent with the experimental results.

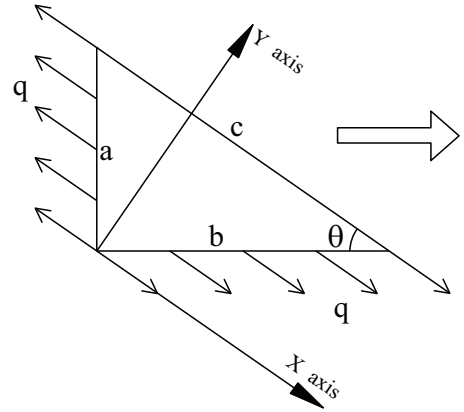

(a)

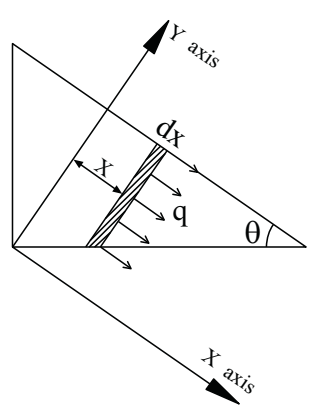

(b)
Fig. (18). Calculation model of extended end-plate stiffener.

\section{CONCLUSION}

The behaviors and the capacities of two extended endplate connections were investigated by using monotonic tests and FEM analysis. The following main conclusions can be drawn:

1. Both the moment resistance and the rotational stiffness of the joint increase when extended end-plate stiffeners are added to the connection. Meanwhile, the plastic hinge shifts to the beam from the panel zone, and the performance of the beam is optimized. The column stiffener, which significantly influenced the overall deformation of the joint, has a dramatic effect on the structural behavior of the column.

2. The influence of end-plate stiffeners' angle is more significant on the final moment value, and on the structure's overall strength. As the end-plate stiffener angle changes from $45^{\circ}$ to $63^{\circ}$, the shear transfer path from the panel zone to the beam also changes, resulting in improvements of the initial rotational stiffness and bearing capacity.

3. The effect of end-plate stiffeners' thickness on shear efficiency is more obvious than strength. With increasing stiffener thickness, the shear transfer efficiency of the panel zone decreases, and the shear transfer efficiency is maximized when the thickness of the stiffener is equal to the web thickness $(6 \mathrm{~mm})$.

4. The numerical results calculated from the two FEMs are acceptable compared with the experimental results. Numerical method 1 can reflect the stress distribution, plastic progress, and failure modes of entire joints. The result of method 1 is more consistent with experiment because of the accurate three-dimensional modeling, however, this approach is complex and time-consuming. The calculation error obtained by method 2 is a little bigger because the components and constraints are simplified, while this method can more clearly determine the performances of each joint component and is simpler and less time-consuming.

\section{CONFLICT OF INTEREST}

The authors confirm that this article content has no conflict of interest.

\section{ACKNOWLEDGEMENTS}

This study was supported by the National Nature Science Foundation of China (No.51178192, No. 51378219), State Key Lab of Subtropical Building Science, South China University of Technology (No. 2012ZA05).

\section{REFERENCES}

[1] CEN. Eurocode 3: Design of steel structures--Part 1.8: Design of joints, EN 1993-1, Brussels, Belgium, 2005.

[2] L. S. da Silva, "Towards a consistent design approach for steel joints under generalized loading", Journal of Constructional Steel Research, vol. 64, pp. 1059-1075, 2008.

[3] M. Kattner, and M. Crisinel, "Finite element modeling of semirigid composite joints", Computers and Structures, vol. 78, pp. 341-353, 2000.

[4] G. Huber, and F. Tschemmernegg, "Modeling of beam-to-column joints: Test evaluation and practical application", Journal of Constructional Steel Research., vol. 45, pp. 199-216, 1998.

[5] H. D. Wright, Y. Wang, and R. Cairns, "Modeling of semi-rigid composite joints", Proceedings of International Conferences on Advances in Structures, vol. 3, pp. 745-750, 2003.

[6] V. Piluso, G. Rizzano, and I.Tolone, "An advanced mechanical model for composite connections under hogging /sagg-ing moments", Journal of Constructional Steel Research, vol. 72, pp. 35-50, 2012.

[7] W. F. Chen, and F. M. Liu, "Stability design of steel frames", Boca Raton: CRC Press, 1991.

[8] Y. J. Shi, S. L. Chan, and Y. L. Wong, "Modeling for momentrotation characteristics for end plate connections", Journal of Structural Engineering, vol. 122, pp.1300-1306, 1996. 
[9] GB 50017-2003, Code for Design of Steel Structures, China Planning Press, Beijing, 2003 (in Chinese).

[10] W. L. Li, "Behavior of semi-rigid beam-to-column minor axis connections in steel frames", Ph.D. thesis, Xi'an University of Architecture \& Technology, Xi'an, China, 2007.

[11] J. Gao, W. L. Shi, G. Q. Li, and Z. M.Ye, "Initial rotational stiffness of semi-rigid composite beam-to-column joints with flush end plate connections", Engineering Mechanics, vol. 28, pp. 55-61, 2011 (in Chinese).

[12] S. F. Wang, and Y. Y. Chen, "Theoretical model for the initial stiffness of bolted T-stub connection”, Industrial Construction, vol. 37, pp. 80-83, 2007 (in Chinese).
[13] W. Zhan, and W. Tao, "Experiment and finite element analysis for the end plate minor axis connection of semi-rigid steel frames", China Civil Engineering Journal, vol. 45, pp. 83-89,. 2012 (in Chinese).

[14] M. L. Williams, "Stress singularities resulting from various boundary conditions in angular corners of plates in extension", Journal of Applied Mechanics, vol. 19, pp. 526-528, 1952.

[15] L. K. Hsiao, J. J. Chambers, and W. J. Schultz, "Stress singularity effect on beam flanges in moment connections", Advances in Structural Engineering., vol. 8, pp.143-156, 2005.

[16] W.Zhao, and G.S. Tong, "Test and finite element analysis of endplate stiffeners for extended end-plate connections", China Civil Engineering Journal, vol. 41, pp. 22-30, 2008 (in Chinese).

(C) Chen et al.; Licensee Bentham Open.

This is an open access article licensed under the terms of the Creative Commons Attribution Non-Commercial License (http://creativecommons.org/licenses/by-nc/3.0/) which permits unrestricted, non-commercial use, distribution and reproduction in any medium, provided the work is properly cited. 